
\title{
25 Research Soure \\ Biological Controls of Fusarium Tomato-wilt Disease by the Blue-green Alga Nostoc Spp.
}

\author{
Mostafa M. El-Sheekh
}

Tanta University

Mohamed A. Deyab

Domit University

Reham S. A. Hasan

Soil, Water and Environmental Institute

Seham E. Abu Ahmed

Domit University

Abdelgawad Elsadany ( $\nabla$ cyanogawad@gmail.com )

Cyanobacteria Lab., Microbiology Dept., Soil, Water and Environment Research Institute https://orcid.org/0000-0002-8510-4196

\section{Research Article}

Keywords: Antifungal activity, Cyanobacteria, Fusarium oxysporum f. sp. Iycopersici, Tomato

Posted Date: July 26th, 2021

DOI: https://doi.org/10.21203/rs.3.rs-662113/v1

License: (c) (i) This work is licensed under a Creative Commons Attribution 4.0 International License.

Read Full License 


\section{Abstract}

This study investigates the effect of extract and culture of certain cyanobacteria on pathogenic Fusarium oxysporum $\mathrm{f}$. sp. lycopersici (FOL) that infects tomato (Solanum lycopersicum) plant in vitro and in vivo. Some cyanobacteria isolates were isolated from saline soils of El-Hamoul and Seidy Salem location and identified. Bioactive compounds of isolates were analyzed by GC-MC. Dry weight, carotene, chlorophyll content, and total phenolic compounds of isolates were measured. Plant height $(\mathrm{cm})$, dry weight $(\mathrm{g})$, fruit number, and fruit weight $(\mathrm{g})$ of tomato were estimated. Isolates were defined as Nostoc calcicola and Nostoc linckia. GC/MS analysis showed 49 and 35 bioactive compounds from N. calcicola and N. linckia, respectively. $N$. calcicola possess a higher amount of dry weight, chlorophyll a, carotenoid, and total phenol that measured $670.43 \mathrm{mg} . \mathrm{L}^{-1}, 1.91 \mathrm{mg} / \mathrm{g}$ fresh wt., $466.67 \mu \mathrm{g} / \mathrm{g}$ fresh wt., and $47.00 \mathrm{mg}$ (GAE) g1 , respectively, compared to $N$. linckia. After 100 days, the results showed highest yield values of tomato fruits with Nostoc sp. compared with untreated plants and plants infected with Fusarium.

\section{Introduction}

Agriculture requires extensive use of chemical pesticides to protect crops against pests and diseases. Despite the protective effects of chemical pesticides, they can be harmful to crops, in whole or in part. Several chemicals that may be phytotoxic to plants also pollute soil, groundwater, drinking water, and food (Harman et al. 2004). Excessive use of chemical pesticides to combat pests pollutes the environment. Furthermore, international markets demand that food be clean and devoid of toxins and chemicals. As a result, several governments have made the decision to reduce chemical inputs. As a result, developing alternative pest management methods that lessen our reliance on chemical pesticides is a public concern. Biological control agents, which refers to the use of introduced or resident living organisms such as cyanobacteria, are one of these options. Biological control is sometimes defined as the suppression of one organism's harmful activity by one or more other species (Prasanna et al. 2012). Implementing a biological control agent reduces the effects of pesticide use in the long term and strikes a balance between harmful plant pathogens and their natural enemies. In this regard, antagonistic bacteria and fungi are widely used to control plant diseases (Shahzad et al. 2018). Fusarium oxysporum $f . s p$. lycopersici (FOL) is a highly destructive pathogen that infests greenhouse and field-grown tomatoes in warm vegetable production areas. FOL can be found soilborne, airborne, or as plant residue and is transmitted through any part of the plant (Summeral et al. 2003; Manikandan et al. 2018). Wilt caused by F. oxysporum has appeared as wilted plants with yellowed leaves, which significantly decreases the quantity and quality of the crop (Ajigbola and Babalola 2013; Akram et al. 2013). There may be a 30$40 \%$ yield loss (Kirankumar et al. 2008). Cyanobacteria (blue-green microalgae) are ubiquitous, gramnegative photoautotrophic prokaryotes. They are considered one of the most efficient sources of bioactive secondary metabolites. Known as the spearhead organism in major habitats and possessing diversity in structure, cyanobacteria produce natural products that increase their ability to survive in a variety of environmental conditions. Natural products have been used in disease control for decades. Cyanobacteria have been utilized to develop new drugs that were proven effective in treating incurable 
diseases (Bethan and Carole 2018). They are considered one of the most efficient sources of bioactive secondary metabolites, such as pigments, vitamins, and enzymes (Seddek et al. 2019; Qamar et al. 2021). The presence of various bioactive compounds within the plant and cyanobacteria (secondary or primary metabolites) were recommended for phytopharmaceutical importance (Prakash et al. 2011; Shelk and Bhot 2019). Cyanobacteria are used as antioxidant, anticancer, and antiviral properties that have applications in agriculture, industry, medicine, and biotechnology (Patra et al. 2008). Chemically diverse natural compounds induce cytotoxicity and potentially kill various cells by inducing apoptosis or altering the activation of cell signaling, thus influencing protein kinase-C family members, cell cycle arrest, mitochondrial dysfunctions, and oxidative damage (Qamar et al. 2021). The mode of action of cyanobacteria antimicrobial compounds is damaging the structure or function of the cytoplasmic membrane, destruction of enzymes, and suppression of protein synthesis (Swain et al. 2017). The antimicrobial activity depends on algal species and the type of solvents used (Radhika et al. 2012). Modern advances in biotechnology are geared toward increasing the production of desired products in cyanobacteria for various industrial applications (Abed et al. 2011; Rama et al. 2012; Lau et al. 2015). Cyanobacteria produce a number of biocidal metabolites, including antitumor activity (Yadav et al. 2016; Camila et al. 2018), toxins (Agrawal et al. 2006), and enzyme inhibitors (Skulberg 2000). The present work aimed to explore the inhibitory effect of Nostoc spp. extracts against the tomato-wilt pathogen Fusarium oxysporum f. sp. lycopersici (FOL) in vitro (laboratory) and in vivo (pot experiment). In addition, it aimed to detect the phytochemical components of $N$. spp. extracts by GC/MS analysis.

\section{Materials And Methods}

\section{Study area}

The soil samples were collected from the upper layer $(0-15 \mathrm{~cm})$ of saline clay soil from El-Hamoul and Seidy Salem at Kafr El-Sheikh Governorate, Egypt, to sort and isolate some of the most common cyanobacteria that inhabited these soils (Fig. 1).

\section{Cyanobacteria isolation}

Free- nitrogen $\mathrm{BG}_{11}$ medium was used to isolate $\mathrm{N}_{2}$-fixing cyanobacteria after serial dilutions of the soil samples in an agar medium with an alcohol-sterilized triangle glass rod. Any colored growth that appeared on the agar surface of the Petri dishes was picked out, subcultured, and streaked several times in a new plate. The previous procedure was repeated several times to obtain unialgal cultures with a light microscope (Pringsheim 1949).

\section{Cyanobacteria identification}


For characterization of cyanobacterial isolates, $500 \mathrm{ml}$ Erlenmeyer flasks, each containing $250 \mathrm{~mL}$ of $\mathrm{BG} 11_{0}$ medium and/or plates containing $1 \%$ agarized $\mathrm{BG} 11_{0}$ medium, were inoculated with a loopful of 10 days old culture of each isolate and incubated at $28 \pm 2{ }^{\circ} \mathrm{C}$ under continuous illumination (3000 Lux) for 10 days. The developed colonies were examined for a cultural appearance on solid and liquid media and characteristics of trichomes, sheath vegetative cells, and heterocyst produced by each isolate (Venkataraman 1981) and (Roger and Ardales 1991). The length and the width of the vegetative cells also the width of the sheath, type of spores, presence or absence of hormogonia, presence or absence of spores and its position, number of heterocysts and its repetition, presence of akinte and its type, the nature of cell wall, presence or absence gas vacuoles, as well as pigment color was taken in consideration according to Desikachary (1959).

\section{Cyanobacteria Harvesting}

After the cultivation of cyanobacterial species, the biomass was harvested after the incubation period by centrifugation for $15 \mathrm{~min}$ at 6,000 rpm (Bettina and Gerd 2013).

\section{Estimation of total dry weight}

A definite volume of cyanobacterial culture $(100 \mathrm{ml})$ was centrifuged at $6,000 \mathrm{rpm}$ for $10 \mathrm{~min}$. The precipitated cells were washed twice with distilled water to eliminate the salts, dried overnight in an oven at $50^{\circ} \mathrm{C}$ until constant weight, and weighted (Rafiqul et al. 2005).

\section{Estimation of the chlorophyll a content}

Chlorophyll a content was calculated by Mackinney (1941).

\section{Estimation of carotenoid contents}

A similar procedure for chlorophyll extraction was followed. After that, the pigment extracted was measured at $470 \mathrm{~nm}$, and the amount of carotenoid was estimated by using the extinction coefficient given by Davis (1976).

\section{Estimation of total phenolic compounds}

Total phenolic (TP) contents were determined by the spectrophotometric method of Slinkard and Singleton (1977). The TP was expressed as milligrams of gallic acid equivalents (GAE) per $\mathrm{g}$ of dried sample. 


\section{Preparation of cyanobacterial methanol extracts}

The cells from the exponential phase were centrifuged at 10,000 rpm for $3 \mathrm{~min}$, then filtered through filter paper (Wattman-4) and air-dried (Starr et al. 1962). The dried cell mass of cyanobacteria was extracted by dissolving it in methanol $(1 \mathrm{~g} / 10 \mathrm{ml})$. The supernatant was separated by a filter with a $5 \mu \mathrm{m}$ pore size diameter. The dry residue was re-dissolved in dimethyl-sulfoxide, which is called crude extract $(100 \%)$. Then, they were kept in fresh glass vials in the dark at $4{ }^{\circ} \mathrm{C}$ until they were using for phytochemical screening by GC/MS (Lefort et al. 1988).

\section{Gas chromatography-mass spectrophotometry (GC/MS) analysis}

The GC/MS is a direct and fast analytical method used for the identification of cyanobacterial extracts. Extracts of Nostoc calcicola and Nostoc linckia were obtained using Trace GC-TSQ Quantum mass spectrometer (Thermo Scientific, Austin, TX, USA) with a direct capillary column TG-5MS $(30 \mathrm{~m} \times 0.25$ $\mathrm{mm} \times 0.25 \mu \mathrm{m}$ film thickness). The column oven's temperature was initially held at $50^{\circ} \mathrm{C}$ and then increased by $5^{\circ} \mathrm{C} / \mathrm{min}$ to $200^{\circ} \mathrm{C}$ and held for $2 \mathrm{~min}$. Then, it was further increased to the final temperature of $290^{\circ} \mathrm{C}$ by $30^{\circ} \mathrm{C} / \mathrm{min}$ and held for $2 \mathrm{~min}$. The injector and MS transfer line temperatures were kept at $270^{\circ} \mathrm{C}$ and $260^{\circ} \mathrm{C}$, respectively. The carrier gas was helium at a constant flow rate of $1 \mathrm{ml} / \mathrm{min}$.

\section{Fungus cultivation}

Potato dextrose agar (PDA) medium was used to cultivate the plant pathogenic fungus Fusarium oxysporum $f$. sp. lycopersici (FOL), then incubated at $28^{\circ} \mathrm{C} \pm 2{ }^{\circ} \mathrm{C}$ for $3-5$ days and stored on PDA slants at $4^{\circ} \mathrm{C}$ until use.

\section{Antifungal activity using cyanobacterial isolates (the disk diffusion test).}

The antifungal activities of cyanobacterial extracts and cultures were evaluated by using an agar plate diffusion test. Plates were incubated at $37^{\circ} \mathrm{C}$, and the inhibition zones were measured (Lefort et al. 1988).

\section{Pot Experiment (50 days, 100 days)}

\section{Fungal inoculum preparation}


The selected phytopathogenic fungus Fusarium oxysporum was multiplied using sorghum seeds (Sorghum bicolor) moistened with water in equal proportions and autoclaved thrice for 90 min on three consecutive days (Paulitz and Schroeder, 2005). Flasks were inoculated within one-week-old fungal mycelium grown on PDA media and incubated at room temperature $\left(27^{\circ} \mathrm{C} \pm 2^{\circ} \mathrm{C}\right)$ for four weeks, shaking at weekly intervals. Colonized sorghum seeds were used as fungal inoculum at a rate of $50 \mathrm{~g}$ in $500 \mathrm{~g}$ of potting mix. Sterilized soil was inoculated with the FOL spores $\left(1.0 \times 10^{3} \mathrm{spores} / \mathrm{g}\right.$ of soil mixture). Pots were filled with $5 \mathrm{Kg}$ of soil; two seedlings of tomato grown in soil were transplanted into each pot (24 pots $\times 3$ ). Three times were carried out.

\section{Preparation of seedlings}

Tomato (Lycopersicon esculentum L.) seeds were surface sterilized ( $0.1 \%$ sodium hypochlorite), then washed three times. The seeds of the two cyanobacterial species ( $N$. calcicola and N. linckia) were soaked in cyanobacterial methanol extract and cyanobacterial culture at room temperature $\left(27^{\circ} \mathrm{C} \pm 2^{\circ} \mathrm{C}\right)$ for 24 hours. Then, the seeds were grown in a greenhouse and were transferred gently after growing for one month in the previously prepared pots. Seedlings without any inoculation served as the control.

Pots were arranged in a glass house on a rack and watered as required. Then, $5 \mathrm{ml}$ of extract and $10 \mathrm{ml}$ of culture were added to each treatment as an inoculum 3 times every two weeks. Plants were observed daily to record symptoms and growth. After 50 days, plant height, fresh weight, dry weight, and chlorophyll were recorded. Ripe fruits were collected daily and their numbers and weight were recorded. After 100 days, the plants were collected. Then, the plant length and dry weight were recorded, following a method described by Perveen et al. (2007), with slight modifications.

\section{Estimation of photosynthetic pigments for tomato plant}

The photosynthetic pigments (chlorophyll a, b, and carotenoids) were determined as $\mathrm{mg} / \mathrm{ml}$. They were estimated from the apex of the third leaf after 50 and 60 days using the spectrophotometric method of Metzner et al. (1965), and they were applied to higher plants by Ahmed et al. (1977).

Chlorophyll a $(\mathrm{mg} / \mathrm{ml})=10.3 \mathrm{~A}(663)-0.918 \mathrm{~A}(644)$.

Chlorophyll b $(\mathrm{mg} / \mathrm{ml})=19.7 \mathrm{~A}(644)-3.87 \mathrm{~A}(663)$.

Carotene $(\mathrm{mg} / \mathrm{ml})=4.2 \times \mathrm{A}(452 \mathrm{~nm})-(0.0246 \times \mathrm{Chl} \mathrm{a}+0.426 \times \mathrm{chl} b)$

The results obtained from these equations were expressed as $\mathrm{mg} / \mathrm{g}$ of fresh matter from all extraction using different treatments. Measurements were carried out in light within a maximum of six hours to avoid the decomposition of pigments. 


\section{Statistical analysis}

The collected data were subjected to statistical analysis using SPSS version 22 and (Steel and Torrie, 1980).

\section{Results And Discussion}

The physical and chemical characteristics of the collected soil samples are presented in Table 1. Soils were classified as saline due to the large variation between those samples in electric conductivity, which ranged from 6.32 to $15.93 \mathrm{dS} \cdot \mathrm{m}^{-1}$. The cyanobacterial species were $N$. calcicola, which were located in sites 6, 7, and 8, in Seidy Salem; and N. linckia, which was located in the Seidy Salem site (13) and ElHamoul site (10), as shown in Fig. 1. This relative frequency distribution reflects the fact that cyanobacteria can live in all environmental conditions, which agreed with findings by Muruga et al. (2014).

\section{Cyanobacterial isolates}

The cyanobacterial isolates $N$. calcicola and $N$. linckia were described by EL-Gamal et al. (2008) in Fig. 2 , respectively. The pictures were taken by an OPTICA microscope (Italy) fitted with a Canon Powershot G12 digital camera.

\section{Total dry weight and pigment contents of cyanobacteria}

The total dry weight and pigments were among the most important factors for de cyanobacterial growth, especially chlorophyll a. Their biomass is one of the most beneficial bio-fertilizers, which improves soil characteristics such as water-holding capacity and improvements of mineral nutrients (Singh et al. 2016; Ramírez et al. 2019). As shown in Fig. 3, N. calcicola recorded $670.43 \mathrm{mg}$ dry wt. /L followed by N. linckia $577.38 \mathrm{mg}$ dry wt. /L. These results were in agreement with Hegazi et al. (2010). Cyanobacterial growth also belongs to their chlorophyll and carotenoids at harvesting time (exponential phase). The highest chlorophyll a and carotenoid contents were of $N$. calcicola, followed by $N$. linckia, representing 1.91, 466.67 and $1.64,350.67 \mathrm{mg}$ per $\mathrm{g}$ fresh wt., respectively. Statistical analysis revealed a highly significant difference in the content of chlorophyll of tested cyanobacteria. Photosynthetic pigments like chlorophyll and carotenoids were essential for photosynthesis in cyanobacteria as a primary electron donor. These results agreed with those obtained by Zavřel et al. (2015); Park et al. (2018). In addition, photoprotection was simultaneously shared. (Kim 2015).

\section{Estimation of total phenolic compounds}


There were highly significant variations between cyanobacterial species in their total phenol contents. Figure 4 revealed that the total phenols were evaluated to investigate compounds on the antioxidant activities of these extracts. The results showed that as long at the mean value of total phenol content was in the range of 38.0-57.3 mg GAE/g. These agreed with Park et al. (2018).

\section{Gas chromatography/mass spectroscopy (GC/MS) analysis of methanol extract}

Profiling of metabolite has been developed as a new technology platform for investigating biological samples, as it describes complex chemical matrices and identifies various compounds. In particular, $\mathrm{GC} / \mathrm{MS}$ is a fast, precision tool that is commonly used in diagnostics, functional genomics, and screening (Rohloff 2015). The bioactive compounds in $N$. calcicola and $N$. linckia are summarized in Tables 2 and 3. N. calcicola and N. linckia contained numerous bioactive compounds that belong to different classes as fatty acids, phenolics, antioxidants, alkaloids, flavonoids, and steroids, which agrees with Michalak et al. (2016); Guiheneuf et al. (2016).

The major constituents, retention time, concentration (area \%), the chemical structure of bioactive components, molecular formulas, and molecular weight are presented in Table 2 and Fig. 5. $N$. calcicola has forty-nine bioactive compounds, and 9-octadecenoic acid and (Z) methyl ester (Oleic acid) ( $19.48 \%$ ) was the most common, which is used as antimicrobial, antibacterial, antioxidant, anti-arthritic, hypocholesterolemic, and anti-cancer (Lee et al. 2007; Mishra and Shree 2007; Wu et al. 2011). In addition, 12, 15-octadecadienoic acid methyl ester; 9.04\%, p-xylene benzene, 1, 4-dimethyl; 8.25\%, and hexadecenoic acid methyl ester (palmitic acid methyl ester) represent as $6.92 \%$ and must have the antimicrobial activity against different plant pathogen (Liu and Huang 2012; Johannes et al. 2016). Each extract also contains cyclooctasiloxane hexadeca methyl; 3.58\%, and Di-n-octyl phthalate 1,2benzenedicarboxylic acid, dioctyl ester; $3.51 \%$.

$N$. linckia has thirty-five bioactive compounds in the methanolic extract. The most dominant percentage was 10 -octadecenoic acid methyl ester (27.67\%), followed by 9-hexadecenoic acid methyl ester, (Z); $24.10 \%, 12,15$-octadecadienoic acid methyl ester; $10.16 \%$, octacosane (Al3-52615); $4.89 \%$, thieno $(3,4-C)$ pyridine, 1,3,4,7 tetraphenyl; 4.86\%, and 10,13-octadecadienoic acid methyl ester [(methyl $(10 \mathrm{E}, 13 \mathrm{E}) 10,13$ octadecadienoate)]; $2.98 \%$ as represented in Table 3 and Fig. 6 . Linoleic acid is also used in paints, varnishes, coatings, vitamins (O'neil, 2013), beauty products, anti-inflammatory agents, and skin-lightening therapies (Ando et al. 1998; Darmstadt et al. 2002).

As summarized in Tables 2 and 3, there are different species of Nostoc, they have variations in the number, type, arrangement of predominance, and concentration area for each bioactive component. Some cyanobacterial strains have a high source of bioactive secondary metabolites, which can have therapeutic, industrial, and agricultural importance, including findings by Gupta et al. (2013); Rimsha et al. (2014). In the present study, octadecanoic acid, which acts as a plant defense response 
against pathogens (Bihana et al. 2018), and glycine (a good antioxidant) were used to save the kidney and the liver from dangerous side effects of some drugs, alcohol, cancer prevention, memory enhancement, could have been used directly on the skin to treat leg ulcers and heal other wounds (Szabo and Nemeroff 2015) were among the identified compounds. 1-hexadecene, which possesses antibacterial activity (Beevi et al. 2014), propanoic acid, phenol, vitamin E, and $\mathrm{K}$ with antimicrobial and antitumor properties (Venkatachalam et al. 2013; Rangel-Sánchez et al. 2014) were also presented in the Nostoc spp. extracts.

\section{Effect of cyanobacterial isolates on the mycelial growth of pathogenic fungi}

Figure 7 shows that all the tested cyanobacterial species in the methanol extract and culture) have highly significant differences between the two cyanobacterial species. N. calcicola and N. linckia exhibited antifungal activity against Fusarium oxysporum (FOL) in vitro after 8 days of incubation.

The antifungal activities of the tested cyanobacteria could be arranged in the following sequence $N$. calcicola $($ extract) $>N$. linckia (extract) $>N$. linckia (culture) $>N$. calcicola (culture), which were16.66, $16.16,16.0,15.33 \mathrm{~mm}$ respectively. The results revealed that extracts exhibited higher antifungal activity than the culture. These results agreed with Mostafa et al. (2009).

\section{Pot experiment}

The pot experiment shows the role of inoculation for some cyanobacteria, such as $N$. calcicola and $N$. linckia, on the root, shoot length, fruit number, and weight of tomato. The experiment was divided into two stages after 50 and 100 days. The differences between the two phases as differences between the extracts and the culture for each species were observed.

Cyanobacteria have phytochemical compounds, which enhance plant growth and increase its tolerance to stress conditions (Buzi et al. 2004; Faoro et al. 2008). The levels of phytoalexins, which were a large and structurally diverse group of antimicrobial plant defense compounds, increased following pathogen inoculation or elicitation (Echeverri et al. 1997; 2012). These substances affect the gene expression of the host plants, thereby bringing about qualitative and quantitative changes in the phytochemical composition of plants. The elicitors and signaling compounds involved in phytochemical responses have been identified as belonging to groups of carbohydrate, lipids, glycolipids, or glycoproteins (Ebel and Cosio 1994; Hahn 1996).

\section{(A) Pot experiment after 50 days}


The results in Table 4 show highly significant differences among the different species. The plant height of Nostoc spp. was arranged in the following sequence: $N$. calcicola (culture); $14.40 \mathrm{~cm}, N$. calcicola (extract); $14.00 \mathrm{~cm}, N$. linckia (extract); $13.87 \mathrm{~cm}$, and $N$. linckia (culture); $13.50 \mathrm{~cm}$ compared with Control 1 (without any addition), which represented $14.17 \mathrm{~cm}$, and the highest plant recorded for Fusarium (Control 2); $14.67 \mathrm{~cm}$. From these results, it became clear that Fusarium achieved clear plant growth according to the plant height, and there was a similarity with Minerdi et al. (2011); Splivallo et al. (2007). Also, the pathogen increases the growth of the plant, but for a limited period, then there is a drop in the growth of the plant, due to the fact that the fungus secretes substances that encourage growth during this period and this agreement with (Mace 1965; Manners 1982) found that the auxin IAA is produced by $F$. oxysporum f. sp. and affect growth and development of the plant, or by affecting the production of plant growth hormones by the host or degradation of hormones in the tissues.

The plant fresh weight of the tested cyanobacteria was arranged in the following sequence: $N$. linckia (culture) $>N$. calcicola (culture) $>N$. calcicola (extract) $>N$. linckia (extract). On the other hand, the dry weight recorded for $N$. linckia extract was higher than its culture, but $N$. calcicola exhibited the same fresh weight. Both fresh and dry weights were compared with Control 2 (with Fusarium only), which represented $5.76 \mathrm{~g}$ and $0.67 \mathrm{~g}$, respectively, and the highest weight recorded in Control 1 (without any addition) achieved $10.56 \mathrm{~g}$ and $0.90 \mathrm{~g}$, respectively. These results were in agreement with Alwathnani and Perveen (2012).

\section{Chlorophyll a}

Figure 8A shows that after 50 days, chlorophyll a was arranged as $N$. calcicola (extract); 63.39 $\mu \mathrm{g} / \mathrm{g}, N$. calcicola (culture); $55.47 \mu \mathrm{g} / \mathrm{g}, N$. linkia (culture); $54.74 \mu \mathrm{g} / \mathrm{g}$, and $N$. linkia (extract); and 54.20 $\mu \mathrm{g} / \mathrm{g}$ compared with Control 1 (without cyanobacteria) and Control 2 (with Fusarium) were recorded as 41.81 and $57.93 \mu \mathrm{g} / \mathrm{g}$, respectively. After 60 days, chlorophyll a appeared in the following arrangement: $N$. linkia (extract); 34.30, N. calcicola (extract); 32.84, N. linkia (culture); 30.52, and N. calcicola (culture); $26.79 \mu \mathrm{g} / \mathrm{g}$. All these were compared with Control 1 (without cyanobacteria), $23.09 \mu \mathrm{g} / \mathrm{g}$, and Control 2 (with Fusarium), $28.68 \mu \mathrm{g} / \mathrm{g}$. Application of cyanobacteria were improved the chlorophyll a, b, leaf area, gibberellin, carotenoids, and height of the plant (Yanni et al. 2020; El-Habet and Elsadany 2020; Geries and Elsadany 2021).

\section{Chlorophyll b}

After 50 days, the chlorophyll b contents were 25.54, 26.33, 25.62, 25.55, and $25.54 \mu \mathrm{g} / \mathrm{g}$ for $N$. calcicola (extract), N. linckia (culture), N. calcicola (culture), and N. linckia (extract), respectively, compared with the infected plants with Fusarium (Control 2), $25.89 \mu \mathrm{g} / \mathrm{g}$, and the untreated plant with cyanobacteria (Control 1), $26.82 \mu \mathrm{g} / \mathrm{g}$. On the other hand, chlorophyll b contents after 60 days were recorded in plants treated with N. linckia (culture), N. calcicola (culture), N. calcicola (extract), and N. linckia (extract), which 
represented 16.31, 16.09, 15.58, and $14.45 \mu \mathrm{g} / \mathrm{g}$, respectively, compared with Control 2 (for Fusarium only), $15.61 \mu \mathrm{g} / \mathrm{g}$, and Control 1 (without any addition), $17.31 \mu \mathrm{g} / \mathrm{g}$ (Fig. 8B).

The maximum value of chlorophyll $a+b$ peaked after 50 days, then started to decline. Chlorophyll $a+b$ increased significantly in all treated plants as compared to the FOL inoculated Control 1 . The maximum value was observed in $N$. calcicola (extract) treated plants due to its high contents of biochemicals that were concentrated in its extract. These results agreed with Alwathnani and Perveen (2012).

\section{Carotene}

Figure $8 \mathrm{C}$ showed that the maximum carotene content after 50 days was observed in plants treated with $N$. calcicola (extract) $(3.479 \mu \mathrm{g} / \mathrm{g})$ followed by $N$. linkia (extract) $(3.11 \mu \mathrm{g} / \mathrm{g}), N$. linkia (culture) $(3.088$ $\mu \mathrm{g} / \mathrm{g})$, and $N$. calcicola (culture) $(3.054 \mu \mathrm{g} / \mathrm{g})$. The carotene content after 60 days of tested cyanobacteria could be arranged in the following arrangement: N. calcicola (extract), $>N$. linkia (culture) $>N$. calcicola (culture) $>N$. linkia (extract), which were represented as $2.20,2.19,2.06$, and $1.87 \mu \mathrm{g} / \mathrm{g}$, respectively. These results were compared to plants that were not treated with cyanobacteria (Control 1) at $1.77 \mu \mathrm{g} / \mathrm{g}$, or the Control 2. The case of plants infected with Fusarium at $1.64 \mu \mathrm{g} / \mathrm{g}$. The carotene level increased in the tomato plant. These results are shown in Fig. 8C and Fig. 9; when treated by cyanobacteria, as reported by Saniewski and Czapski (1983).

\section{(B) Pot experiment after 100 days}

\section{Plant height (cm) and dry weight $(\mathrm{g})$ of tomato}

Data in Table 5 shows a highly significant difference among samples. The maximum plant height was observed in plants treated with $N$. linckia (culture) $(30.33 \mathrm{~cm})$, followed by $N$. calcicola (culture) $(29.33 \mathrm{~cm}), N$. calcicola (extract) $(29.33 \mathrm{~cm})$, and $N$. linckia (extract) $(28.00 \mathrm{~cm})$. On the other hand, the maximum dry weight was observed in plants treated with $N$. linckia (culture), $34.27 \mathrm{~g}$; followed by $N$. linckia (extract), $27.83 \mathrm{~g} ;$ N. calcicola (culture), $26.84 \mathrm{~g}$; and N. calcicola (extract), $26.73 \mathrm{~g}$. The fungicidal activity of culture filtrates of Nostocspp. was attributed to the presence of bioactive compounds, which are employed as natural defense mechanisms against pathogenic fungi and bacteria. These agreed with Zee Shan et al. (2010). The same observations were reported by Mostafa et al. (2009). Both plant height and dry weight were compared to those control 1 (plants un-treated with cyanobacteria) and those control 2 (plants infected with Fusarium). These results agree with Alwathnani and Perveen (2012), who said it is evident that plant height and fresh and dry weights have increased in all treated plants compared to those of the FOL inoculated control.

\section{Number and weight (g) of tomato fruit}


Figures $10 \mathrm{~A}$ and $\mathrm{B}$ show a very high significant difference between samples in fruit weight and number after 100 days, respectively. They were recorded in the following order: $N$. linckia (culture) $>N$. linckia (extract) $>N$. calcicola (culture) $>N$. calcicola (extract) compared to Control 1 and Control 2. These results agreed with Mostafa et al. (2009).

Figure 11 shows a clear appearance in the two control plants. Fusarium appeared dead, and tomato fruits appeared dry. Nostoc spp. was successful as an antagonist against Fusarium oxysporum lycopersici, which agreed with Chaudhary et al. (2012). The inhibitory effect of antifungal compounds may be due to their ability to inhibit spore germination or the fungal cell wall component, which alters the permeability of fungal cell membranes, as reported by Gupta et al. (2013). Awad et al. (2009) also reported that antifungal substances might inhibit lipid synthesis in the tested pathogenic fungi due to a decrease in the ratio of unsaturated to saturated fatty acids.

\section{Conclusions}

The present work indicated that $N$. calcicola and $N$. linckia were the most predominant cyanobacterial species in the collected soil samples at the study sites. $N$. calcicola recorded higher dry weight parameters, chlorophyll a, carotenoid, and total phenol than those of $N$. linckia. On the other hand, using the extract for both species achieved higher results in vitro and at the beginning of the pot experiment (in vivo), but at the end of the experiment, the results of the culture were higher than that of the extract. There was an improvement in the yield of tomatoes treated with Nostoc spp. Consequently, N. calcicola and N. linckia were considered to be biological control agents against Fusarium oxysporum $f$. sp. lycopersici $(F O L)$ on tomato plants, and it is a promising strategy for sustainable agriculture

\section{Declarations}

\section{Acknowledgments}

The authors would like to thank Dr. Abdullah A. Saber, Botany Dept., Fac., Science, Ain Shams University, Cairo, Egypt, for identifying the cyanobacterial strains. Thanks are extended to all staff members in the Cyanobacteria Research Lab., Soils, Water and Environment Research Institute- Sakha Agricultural Research Station, Kafrelsheikh, Egypt.

\section{Compliance with ethical standards}

\section{Conflict of interest:}

The authors declare that they have no conflict of interest.

\section{References}


1. Abed RMM, Dobrestov S, Al-Kharusi S, Schramm A, Jupp B, Golubic S (2011) Cyanobacterial diversity and bioactivity of inland hypersaline microbial mats from a desert stream in the Sultanate of Oman. Fottea 11(1):215-224

2. Agrawal M, Ghosh S, Bagchi D (2006) Occurrence of microcystin-containing toxic water blooms in Central India. J Microbiol Biotech 16(1):212-218

3. Ahmed M (2011) Management of Fusarium wilt of tomato by soil amendment with Trichoderma koningii and a white sterile fungus. Indian J Res 5(1):35-38

4. Ajigbola CF, Babalola 00 (2013) Integrated Management Strategies for Tomato Fusarium Wilt. Biocontrol Sciences 18(3):117-127

5. Akram W, Mahboob A, Javel AA (2013) Bacillus thuringiensis strain 199 can induce systemic resistance in tomato against Fusarium wilt. Europ J of Mirobiol Immunol 3(4):275-280

6. Al-Wathnani H, Ismet A, Tahmaz RR, Al-Dayel TH, Bakir MA (2012) Bioactivity of natural compounds isolated from cyanobacteria and green algae against human pathogenic bacteria and yeast. $J$ Med Plants Res 6(18):3425-3433

7. Ambati RR, Phang SM, Ravi S, Aswathanarayana RG (2014) Astaxanthin: Sources, Extraction, Stability, Biological Activities and Its Commercial Applications-A Review. Mar Drugs 12(1):128-152

8. Ando H, Ryu A, Hashimoto A, Oka M, Ichihashi M (1998) Linoleic acid and a-linolenic acid lightens ultraviolet-induced hyperpigmentation of the skin. Arch Dermatol Res 290(7):375-381

9. Beevi AH, Maruthupandy M, Priya RJ, Anand M (2014) Characterization of metabolites of Bacilllus subtilis isolated from sea surface microlayer and its antibacterial activity. Int J Pharm Sci Health Care 2(1):15-24

10. Bethan K, Carole L (2018) Secondary metabolites in cyanobacteria /intechopen. 75648

11. Bettina S, Liebezeit G (2013) Biochemical composition, biological activities and toxicological effects of two non-nodularin producing strains of Nodularia spumigena Mertens in Jürgens. J Appl Phycol 25(1):643-660

12. Bihana S, Dhiman A, Singh G, Satija S (2018) Gas chromatography-mass spectroscopy analysis of bioactive compounds in the whole plant parts of ethanolic extract of Asclepias curassavica L. Int J Green Pharm 12(2):107-121

13. Buzi A, Chilosi G, Magro P (2004) Induction of resistance in melon seedlings against soil-borne fungal pathogens by gaseous treatments with methyl jasmonate and ethylene. J Phytopathol 152(8-9):491-497

14. Camila MC, Daniel SM, Jimmy O (2018) The impact of culture conditions on growth and metabolic profiles of freshwater cyanobacteria. J Appl Phycol 30(1):375-384

15. CHaudhary V, Prasanna R, Nain L, Dubey SC, Gupta V, Singh R, Jaggi S, Bhatnagar A (2012) Bioefficacy of novel cyanobacteria-amended formulations in suppressing damping off disease in tomato seedlings. World Journal of Microbiology Biotechnology 28(12):3301-3310 
16. Darmstadt GL, Mao-Qiang M, Chi E, Saha SK, Ziboh VA, Black RE, Santosham M, Elias PM (2001) Impact of tropical oils on the skin barrier: possible implications for neonatal health in developing countries. National Library of Medicine 91(5):546-554

17. Davis BH (1976) Carotenoids in Chemistry and Biochemistry of Plant pigment. Edited by T. W. Goodwin. Academic Press, New York and London 1(1):149-155

18. Desikachary TV (1959) Cyanophyta. ICAR Monograph on Algae, New Delhi. 1-686

19. Ebel J, Cosio EG (1994) Elicitors of plant defense responses. Int Rev Cytol 148(1):1-36

20. Echeverri F, Torres F, Quinones W, Cardona G, Archbold R, Roldan J, Brito I, Luis JG (1997) Danielone, a phytoalexin from papaya fruit. Phytochemistry 44(2):255-256

21. Echeverri F, Torres F, Quinones W, Escobar G, Archbold R (2012) Phenylphenalenone phytoalexins, will they be a new type of fungicide? Phytochem Rev 11(1):1-12

22. El-Gamal AD, Ghanem NAE, El-Ayouty EY, Ehab FS (2008) Studies on soil algal flora in Kafr EL Sheikh Governorate, Egypt. Egyptian J of Phycol 9(1):1-23

23. Faoro F, Maffi D, Cantu D, Iriti M (2008) Chemical- induced resistance against powdery mildew in barley: the effects of chitosan and benzothiadiazole. Biocontrol 53(2):387-401

24. Geries LSM, Abdelgawad Y, Elsadany (2021) Maximizing growth and productivity of onion (Allium cepa L.) by Spirulina platensis extract and nitrogen-fixing endophyte Pseudomonas stutzeri. Arch Microbiol 203:169-181

25. Guihéneuf F, Khan A, Tran LSP (2016) Genetic engineering: a promising tool to engender physiological, biochemical, and molecular stress resilience in green microalgae. Front Plant Sci 7:400

26. Gupta V, Ratha SK, Sood A, Chaudhary V, Prasanna R (2013) New insights into the biodiversity and applications of cyanobacteria (blue-green algae) Prospects and challenges. Algal Res 2(1):79-97

27. Hahn MG (1996) Microbial elicitors and their receptors in plants. Annu Rev Phytopathol 34(1):387412

28. Harjinder S, Khattar JS, Ahluwalia AS (2014) Cyanobacteria and agricultural crops. International Journal of Plant Research 27(1):37-44

29. Harman GE, Howell CR, Viterbo A, Chet I, Lorito M (2004) Trichoderma species- opportunistic, avirulent plant symbionts. Nat Rev 2:43-56

30. Hashimoto H, Uragami C, Cogdell RJ (2016) Carotenoids and photosynthesis. Subcell Biochem 79(1):111-139

31. Hegazi AZ, Mostafa SSM, Ahmed HMI (2010) Influence of Different Cyanobacterial Application Methods on Growth and Seed Production of Common Bean under Various Levels of Mineral Nitrogen Fertilization. Nature Science 8(12):250-261

32. Howida BI, El-Habet, Abdelgawad Y, Elsadany (2020) Maximizing Growth and Productivity of Rice by Using $\mathrm{N}_{2}$-Fixing Anabaena oryzae and Spirulina platensis Extract. J of Plant Production Mansoura Univ 11(11):1105-1114 
33. Johannes E, Litaay MS (2015) The bioactivity of hexadecanoic acid compound isolated from hydroid Aglaophenia cupressina Lamoureoux as antibacterial agent against Salmonella typhi. Int J Biol Med Re 4(1):5469-5472

34. Kim SK (2015) Handbook of Marine Microalgae: Biotechnology Advances. First edition 1-9

35. Kirankumar R, Jagadeesh KS, Krishnaraj PU, Patil MS (2008) Enhanced Growth Promotion of Tomato and Nutrient Uptake by Plant Growth Promoting Rhizobacterial Isolates in Presence of Tobacco Mosaic Virus Pathogen. J Agric Sci 21(2):309-311

36. Lau NS, Matsui M, Abdullah AAA (2015) Cyanobacteria: Photoautotrophic Microbial Factories for the Sustainable Synthesis of Industrial Products. Bio Med Research International 2015:1-9

37. Lee YS, Kang MH (2007) Effect of constituents of amount Xanthioides on gastritis in rats and on growth of gastric cancer cell. Arch Pharm Res 30(2007): 436-443

38. Lefort TM, Pouphil M, Spathj S, Packer L (1988) Cytoplasmic membrane changes during adaptation of the fresh water Cyanobacterium Synchococcus 6311 to salinity. Plant Physiol 87(3):767-775

39. Letawe C, Boone M, Pierard GE (1998) Digital image analysis of the effect of topically applied linoleic acid on acne microcomedones. Clin Exp Dermatol 23(2):56-58

40. Liu CH, Huang HY (2012) Antimicrobial activity of curcumin- loaded myristic acid microemulsions against Staphylococcus epidermidis. Chem Pharm Bull 60(9):1118-1124

41. Mace ME (1965) Isolation and identification of 3-indoleacetic acid from Fusarium oxysporum $\mathrm{f}$. sp. cubense. Phytopathology 55:240-241

42. Manners JG (1982) Effects of pathogens on metabolism, transport and growth. In: Manners JG (ed) Principles of plant pathology. Cambridge University Press, Cambridge, pp 102-120

43. Mckinney G (1941) Absorption of light by chlorophyll solutions. Journal of Biology Chemistry 140(1):315-322

44. Metzner H, Rau H, Senger H (1965) To synchronsiser bakeit investigations of individual pigmentdeficiency mutants of Chlorella. Planta 65(1):186-194

45. Michalak I, Chojnacka K, Dmytryk A, Wilk R, Gramza M, Rój E (2016) Evaluation of supercritical fluid extract of algae as biostimulants of plant growth in field trials. Front Plant Sci 1577:1591

46. Minerdi D, Bossi S, Maffei ME, Gullino ML, Garibaldi A (2011) Fusarium oxysporum and its bacterial consortium promote lettuce growth and expansin A5 gene expression through microbial volatile organic compound (MVOC) emission. National library of medicine. FEMS Microbiol Ecol 76(2):342351

47. Mishra PM, Shree A (2007) Antibacterial activity and GC MS analysis of the extract of leaves of Finlaysoniaobovata (A Mnagrove Plant). Asi J PI Sci 6(1):168-172

48. Mostafa SM, Abdel El-All AAM, Hussien MY (2009) Bioactivity of algal extracellular byproducts on cercospora leaf spot disease, growth performance and quality of sugar beet. In 4th Conference on Recent Technologies in Agriculture. Faculty of Agriculture, Cairo University 119-129 
49. Muruga BN, Wagacha JM, Kabaru JM, Mugune N (2014) Effect of physicochemical conditions on growth rates of cyanobacteria species isolated from Lake Magadi, a soda lake in Kenya. Web Pub Journal of Scientific Research 2(5):53-62

50. O'neil MJ (2013) The Merck Index-An Encyclopedia of Chemicals, Drugs and Biologicals. (ed.). Cambridge, UK: Royal Society of Chemistry. Journal of medicinal chemistry 50 (3):192-1024

51. Ortiz-Moreno ML, Solarte LV, Sandoval KX (2020) Analysis of Nostoc muscorum biomass production in a hydroponic system. Orinoquia 24(1):23-31

52. Park WS, Kim HJ, Li M, Lim DH, Kim J, Kwak S, Kang C, Ferruzzi MG, Ahn M (2018) Two Classes of Pigments, Carotenoids and C-Phycocyanin, in Spirulina Powder and Their Antioxidant Activities. Journal List Molecules 23(8):2065-2097

53. Patra JK, Rath SK, Jena K, Rathod VK, Thatoi HN (2008) Evaluating of antioxidant and antimicrobial activity of seaweed (Sargassum sp.) extract: A study on inhibition of Glutathione-S transferase activity. Turkish Journal of Biology 32(2):119-125

54. Paulitz TC, Schroede KL (2005) A new method for the quantification of Rhizoctonia solani and $R$. oryzae from soil. Plant Dis 89(7):767-772

55. Perveen K, Haseeb A, Shukla PK (2007) Efficacy of pesticides, neem seed powder and bio-control agents on Meloidogyne incognita and growth and oil yield of Mentha arvensis. Nematol Medit 35(1):75-79

56. Prakash JW, Marimuthu JA, Jeeva S (2011) Antimicrobial activity of certain fresh-water microalgae from Thambirabrani River, Tamil Nadu, South India. Asian Pacific Journal of Tropical Biomedicine 1(1):170-173

57. Prasanna R, Joshi M, Rana A, Shivay YS, Nain L (2012) Influence of co-inoculation of bacteriacyanobacteria on crop yield and $\mathrm{C}-\mathrm{N}$ sequestration in soil under rice crop. World Journal of Microbiology and Biotechnology (Online First ${ }^{\mathrm{TM}}$, 31 October 2011)

58. Pringsheim EG (1949) Pure culture of algae, their preparation and maintenance. Cambridge University Press, London

59. Qamar H, Hussain K, Soni A, Khan A, Hussain T, Chénais B (2021) Cyanobacteria as Natural Therapeutics and Pharmaceutical Potential: Role in Antitumor Activity and as Nanovectors. Molecules 26(1):247

60. Radhika D, Veerabahu C, Priya R (2012) Antibacterial activity of some selected sea-weeds from Gulf of Mannar Coast, South India. Asian Journal of Pharmaceutical Clinical Research 5(4):89-90

61. Rafiqul I, Weber C, Lehmann B, Voss A (2005) Energy efficiency improvements in ammonia production-perspectives and uncertainties. Journal of Renewable Energy 30(13):2487-2504

62. Rajaram K, Moushmi M, Velayutham PDM, Kumpati P, Ganasaraswathi M, Sureshkumar P (2013) Comparative bioactive studies between wild plant and callus culture of Tephrosia tinctoria. Pers Appl Biochem Biotechnol 171(8):2105-2120

63. Ramamurthy V, Raveendran S, Thirumeni S, Krishnaveni S (2012) Antimicrobial activity of heterocytic cyanobacteria. Int J Adv Lif Sc 1:32-39 
64. Ramírez LC, Esparza GFJ, Ferrera CR, Alarcón A, Cañizares VRO (2019) Short-term effects of a photosynthetic microbial consortium and nitrogen fertilization on soil chemical properties, growth, and yield of wheat under greenhouse conditions. J Appl Phycol 31(1):3617-3624

65. Rangel G, Castro E, Garcia E (2014) Avocado roots treated with salicylic acid produce phenol-2,4-bis (1,1-dimethylethyl), a compound with antifungal activity. J Plant Physiol 171(3-4):189-198

66. Rimsha R, Richa J, Sheela K, Shrivastava PN, Manju J (2014) Bio-active substances of cyanobacteria (Nostoc muscorum), a review. Int J Pharma Sci Res 5(7):320-322

67. Rodgers GA, Bergman B, Henriksson E, Uridis M (1979) Utilization of blue-green algae as biofertilizers. Plant Soil 52:99-107

68. Rohloff J (2015) Analysis of Phenolic and Cyclic Compounds in Plants Using Derivatization Techniques in Combination with GC-MS-Based Metabolite Profiling. Molecules 20(2):3431-3462

69. Saniewski M, Czapski J (1983) The effect of methyl jasmonate on lycopene and ß-carotene accumulation in ripening red tomatoes. Experientia 39(1):1373-1374

70. Seddek NH, Fawzy MA, El-Said WA, Ahmed MMR (2019) Evaluation of antimicrobial, antioxidant and cytotoxic activities and characterization of bioactive substances from freshwater blue-green algae. 21(3): 328-336

71. Shahzad S, Rajput AQ, Khanzada MA (2018) Effect of different organic substrates and carbon and nitrogen sources on growth and shelf life of Trichoderma harzianum. J Agr Sci Tec 16(4):731-745

72. Shelke V, Bhot M (2019) GC-MS Analysis of Bio-active Compounds in Ethanolic Extract of Leaf and Stem of Asclepias curassavica L., International Journal of Pharmaceutical Investigation. Int J Pharm Investigation 9(2):67-70

73. Singh JS, Kumar A, Rai AN, Singh DP (2016) Cyanobacteria: a precious bio-resource in agriculture, cosystem, and environmental sustainability. Front Microbiol 21(1):527-529

74. Skulberg OM (2000) Microalgae as a source of bioactive molecules experience from cyanophyte research. J Appl Microbiol 12(3):341-348

75. Slinkard K, Singleton VL (1977) Total phenol analyses: Automation and comparison with manual methods. Am J Enol Vitic 28(1):49-55

76. Splivallo R, Novero M, Bertea CM, Bossi S, Bonfante P (2007) Truffle volatiles inhibit growth and induce an oxidative burst in Arabidopsis thaliana. New Phytol 175(3):417-424

77. Starr TJ, Dieg EF, Church KK, Allen MB (1962) Antibacterial and antiviral activities of algal extracts studies by acridine orange staining. Texas Report on Biology Medicine 20(1):271-278

78. Summeral BA, Salleh B, Leslie JF (2003) A utilitarian approach to Fusarium identification. Plant Dis 87(2):117-128

79. Swain DL, Singh D, Horton DE, Mankin JS, Ballard TC, Diffenbaugh NS (2017) Remote linkages to anomalous winter atmospheric ridging over the northeastern Pacific. J Geophys Res Atmos 122(22):12194-12209 
80. Szabo TS, Nemeroff B, Charles B (2015) Glycine is an excitatory amino acid that can modulate NMDA receptors and the glycine-binding site has been posited as a novel avenue for antidepressant treatment.42 From: Rosenberg's Molecular and Genetic Basis of Neurological and Psychiatric Disease (Fifth Edition). Science direct 5(1):1253-1274

81. Venkatachalam M, Singaravelu G, Govindaraju K, Ahn JS (2013) PTP 1B inhibitory action of a phytochemical propanoic acid, 2-(3-acetoxy-4, 4, 14- trimethylandrost-8-en-17-yl). Curr Sci 105(6):827-831

82. Venkataraman GS (1981) "Blue-Green Algae for Rice Production" - a Manual for Its Promotion. FAO Soils Bull. No. 46. FAO, Rome

83. Wu Y, Liu J, Yang L, Chen H, Zhang S, Zhao H, Zhang N (2011) Allelopathic control of cyanobacterial blooms by periphyton biofilms. Environ Microbiol 13(3):604-615

84. Yadav S, Agrawal M, Raipuria N, Agrawa MK (2016) Antimicrobial activity of Nostoc calcicola (cyanobacteria) isolated from Central India against human pathogens. Asian J Phar 10(4):554:559

85. Yanni YG, Amany A, Elashmouny, Abdelgawad Y, Elsadany (2020) Differential Response of Cotton Growth, Yield and Fiber Quality to Foliar Application of Spirulina platensis and Urea Fertilizer. Asian Journal of Advances in Agricultural Research 12(1):29-40

86. Zavřel T, Sinetova MA, Jan Č (2015) Measurement of Chlorophyll $a$ and Carotenoids Concentration in Cyanobacteria. journal bioprotocol 5(9):2331-8325

87. Zeeshan M, Suhail S, Biswas D, Farooqui A, Arif JM (2010) Screening of selected cyanobacterial strains for phycochemical compounds and biological activities in vitro. Biochem Cell Arch 10(2):163-168

\section{Tables}

Due to technical limitations, tables are only available as a download in the Supplemental Files section.

\section{Figures}




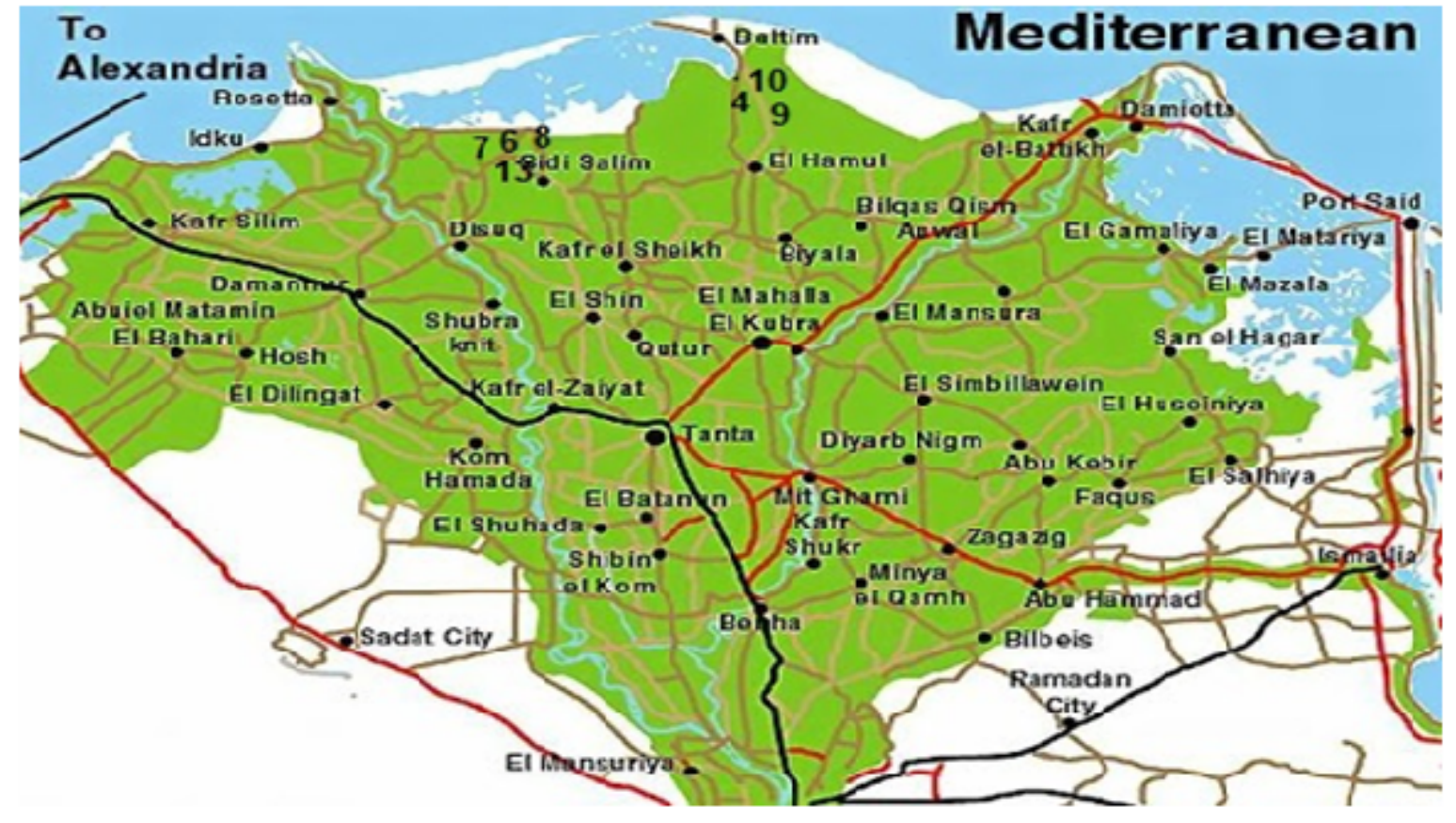

Figure 1

Samples sites at Kafr El-Sheikh centers (1,3,6,7,8 in Sidi Salim, and 4,9,10 in Baltim).

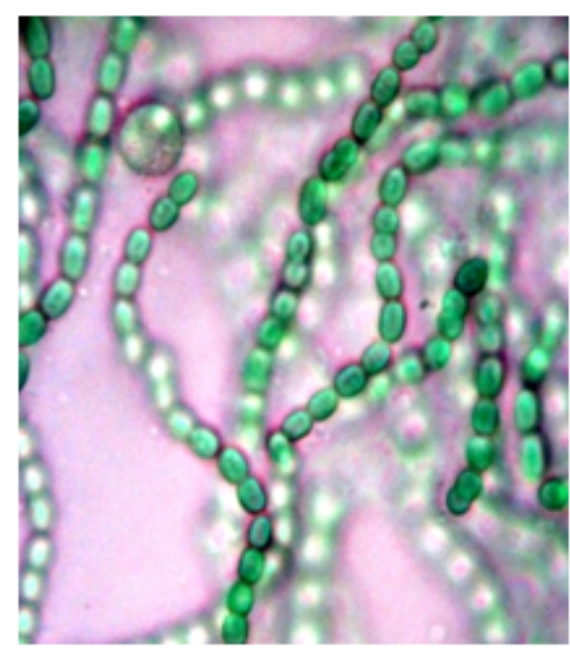

A. N. calcicola

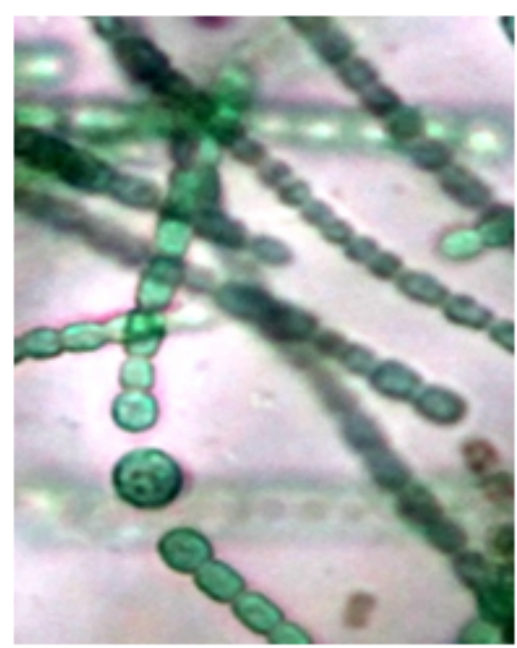

B. N. linkia

\section{Figure 2}

Nostoc spp. under microscope, A. N. calcicola, B. N. linkia 


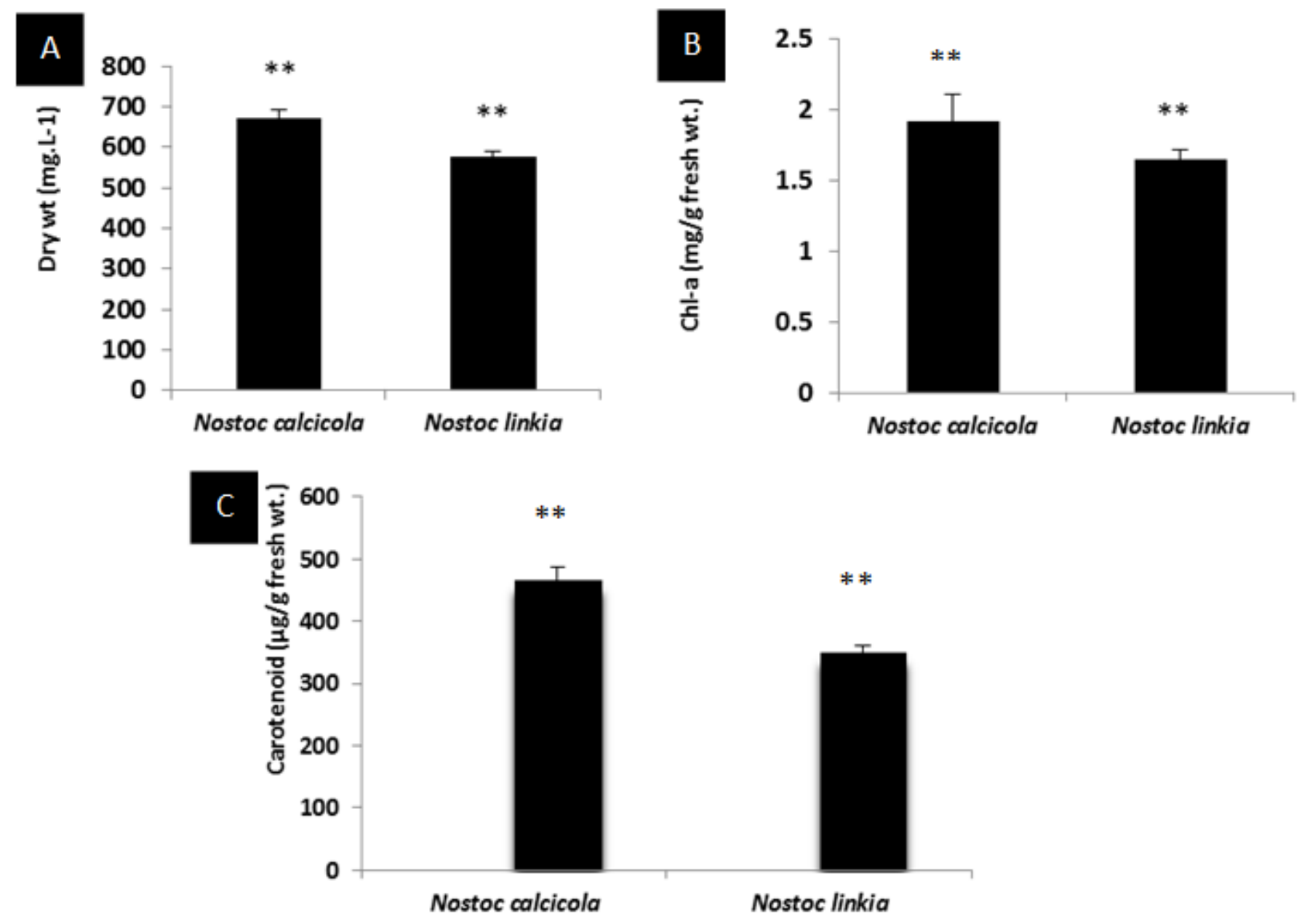

Figure 3

Effect of A. Total dry wt. (mg.L-1), B. Chl-a (mg/g fresh wt.), C. Carotenoid ( $\mu \mathrm{g} / \mathrm{g}$ fresh wt.) on Nostoc spp. growth, $* \star$ very high significant $p \leq 0.01$. 


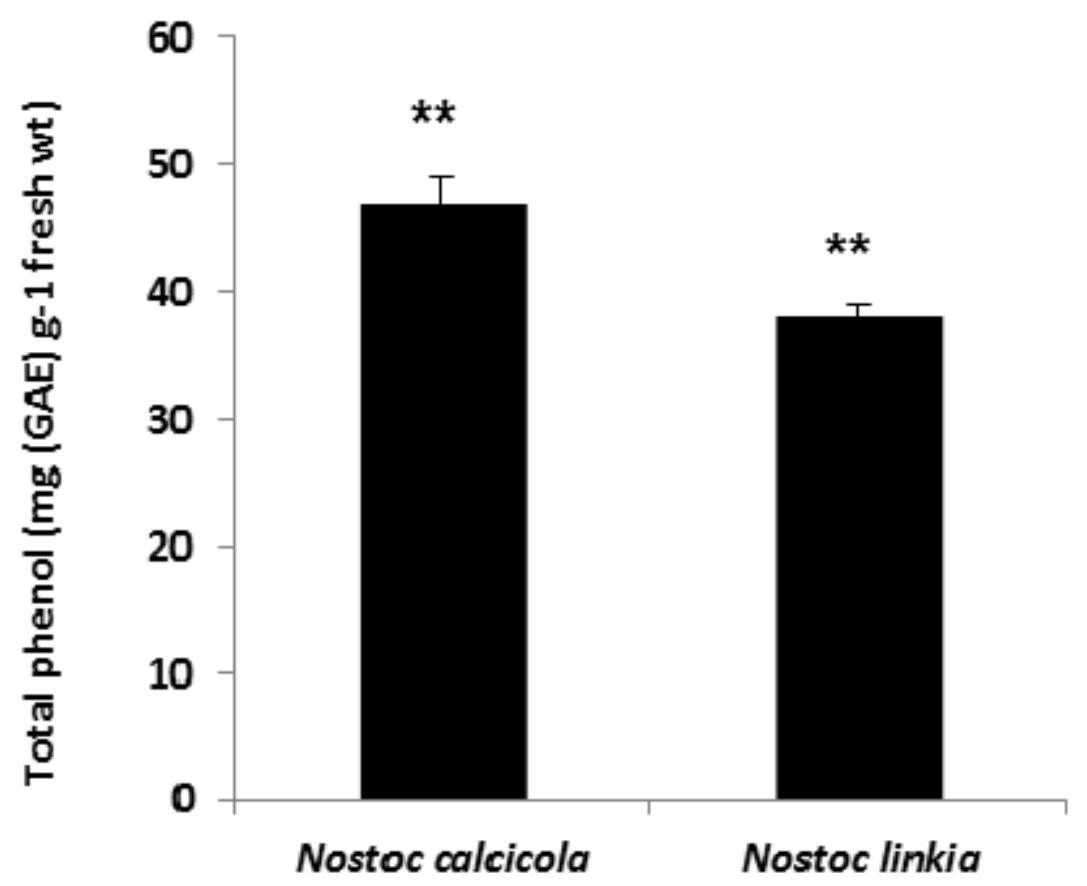

Figure 4

Total phenol content of Nostoc spp. ${ }^{*}$ very high significant $p \leq 0.01$.

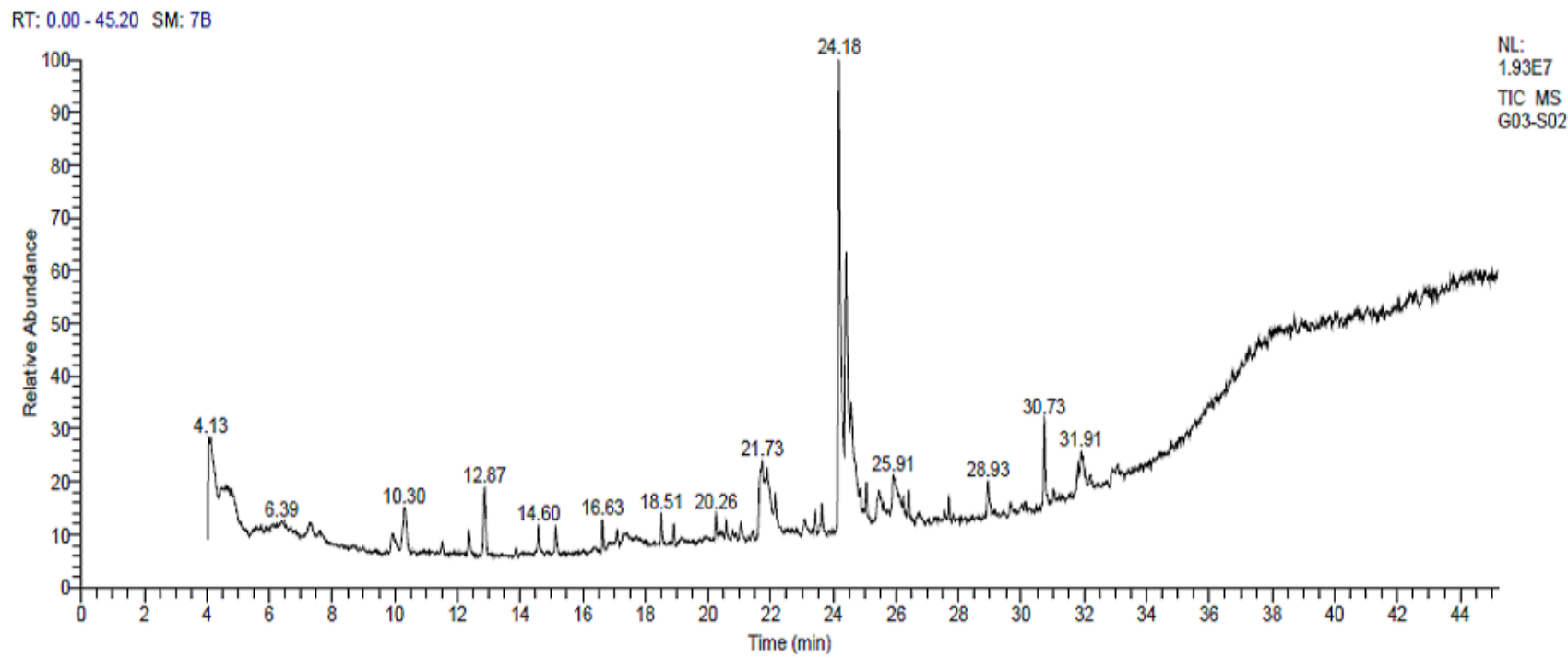

Figure 5

GC/MS chromatogram of N. Calcicola. 


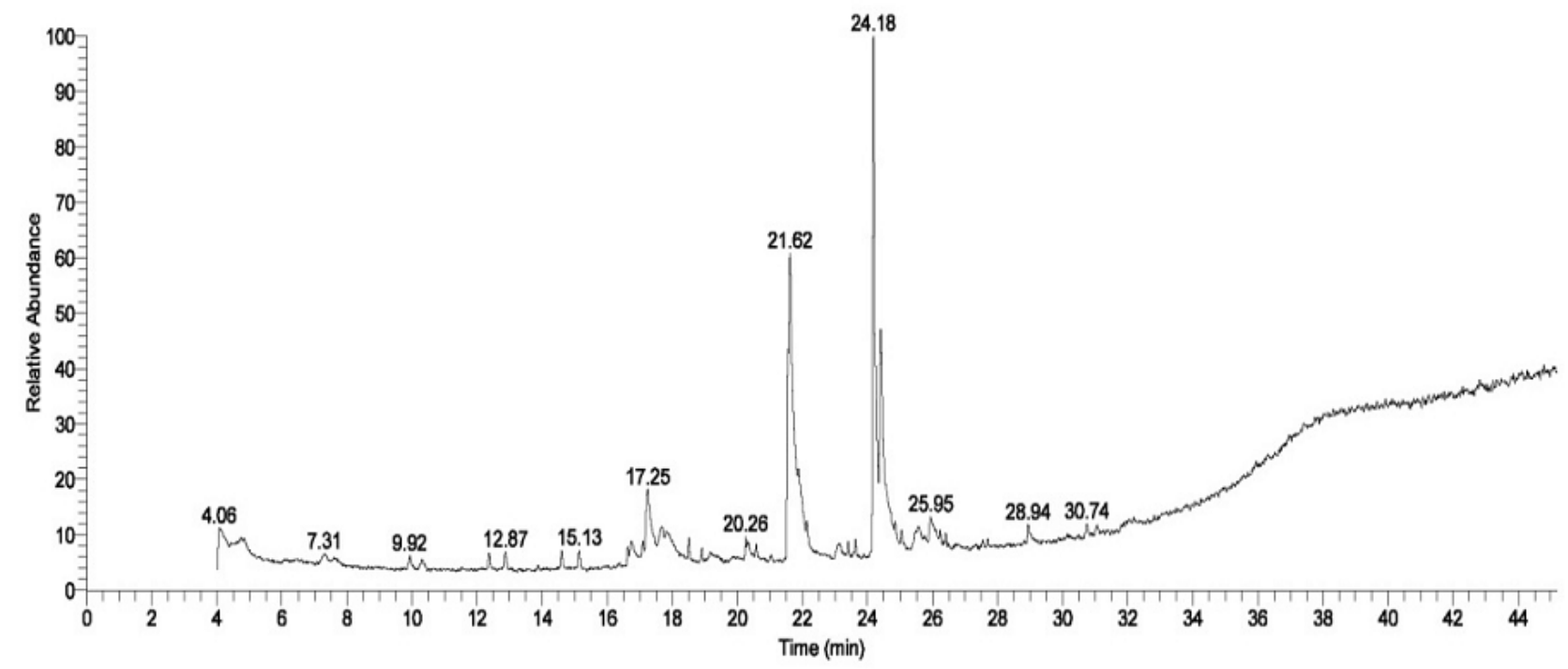

Figure 6

GC/MS chromatogram of N. Linkia.

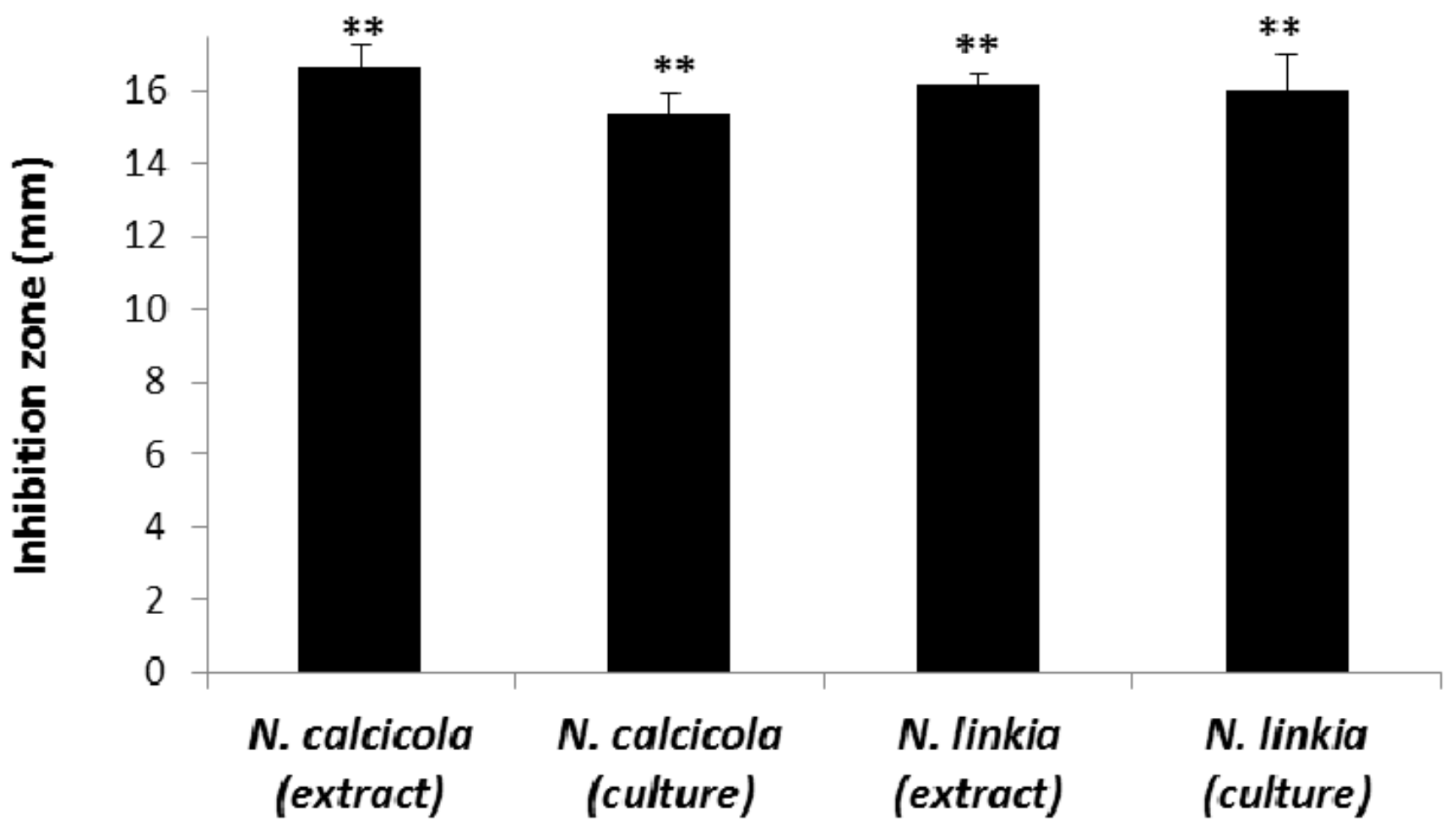

Figure 7

Inhibition zone of Nostoc spp. extract and Culture, ** very high significant $p \leq 0.01$. 

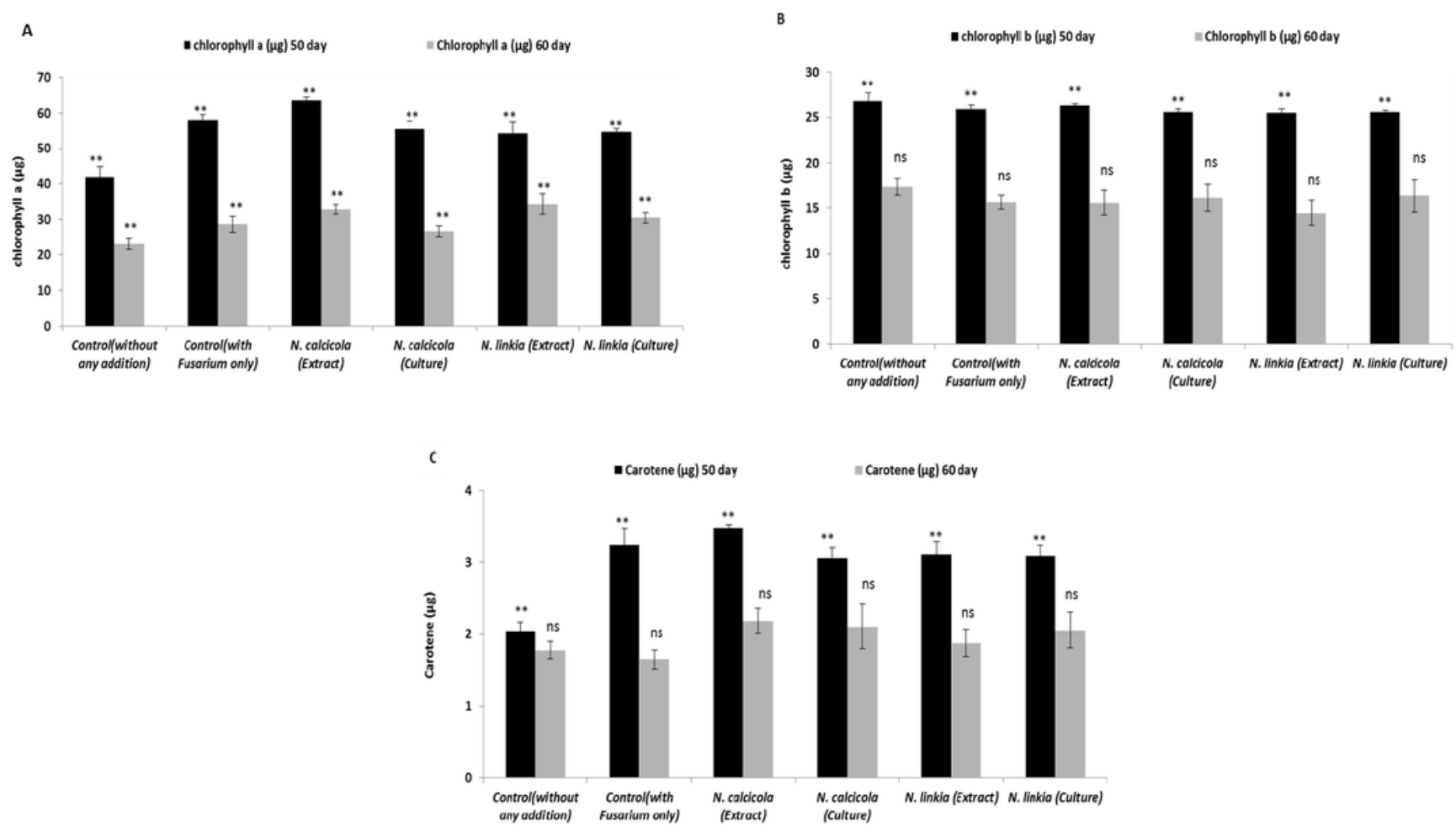

Figure 8

Total pigments contents $(\mu \mathrm{g})$ of tomato plant after 50 and 60 days, A. Chlorophyll-a, B. Chlorophyll-b, C. Carotene, ${ }^{* *}$ very high significant $p \leq 0.01-n s:$ non-significant. 

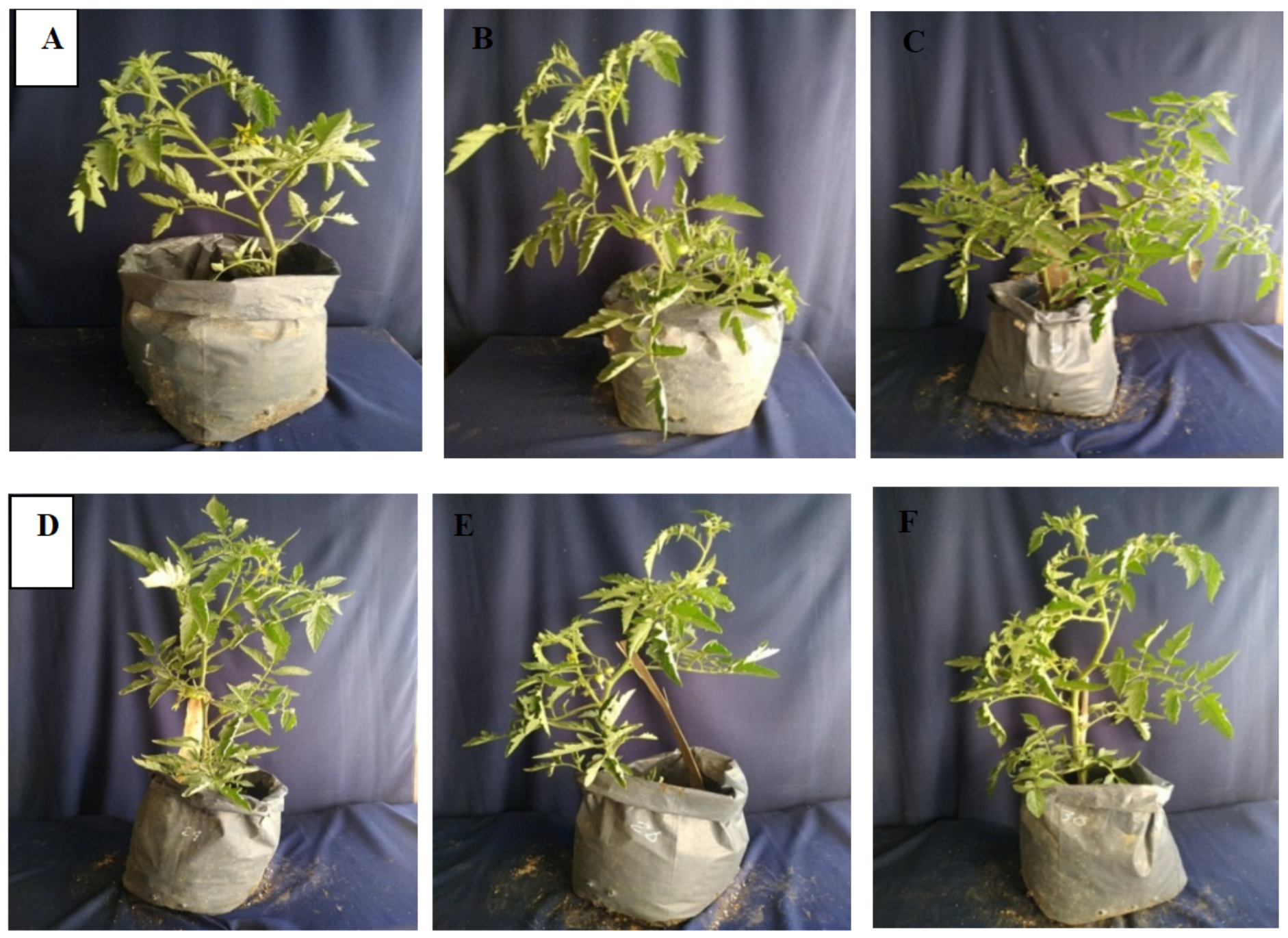

\section{Figure 9}

Pot experiment after 50 days; A- Control 1 (plant without any addition), B- Control 2 (plant infected with FOL), C- N. calcicola extract, D- N. calcicola culture, E- N. linkia extract, and F- N. linkia culture. 

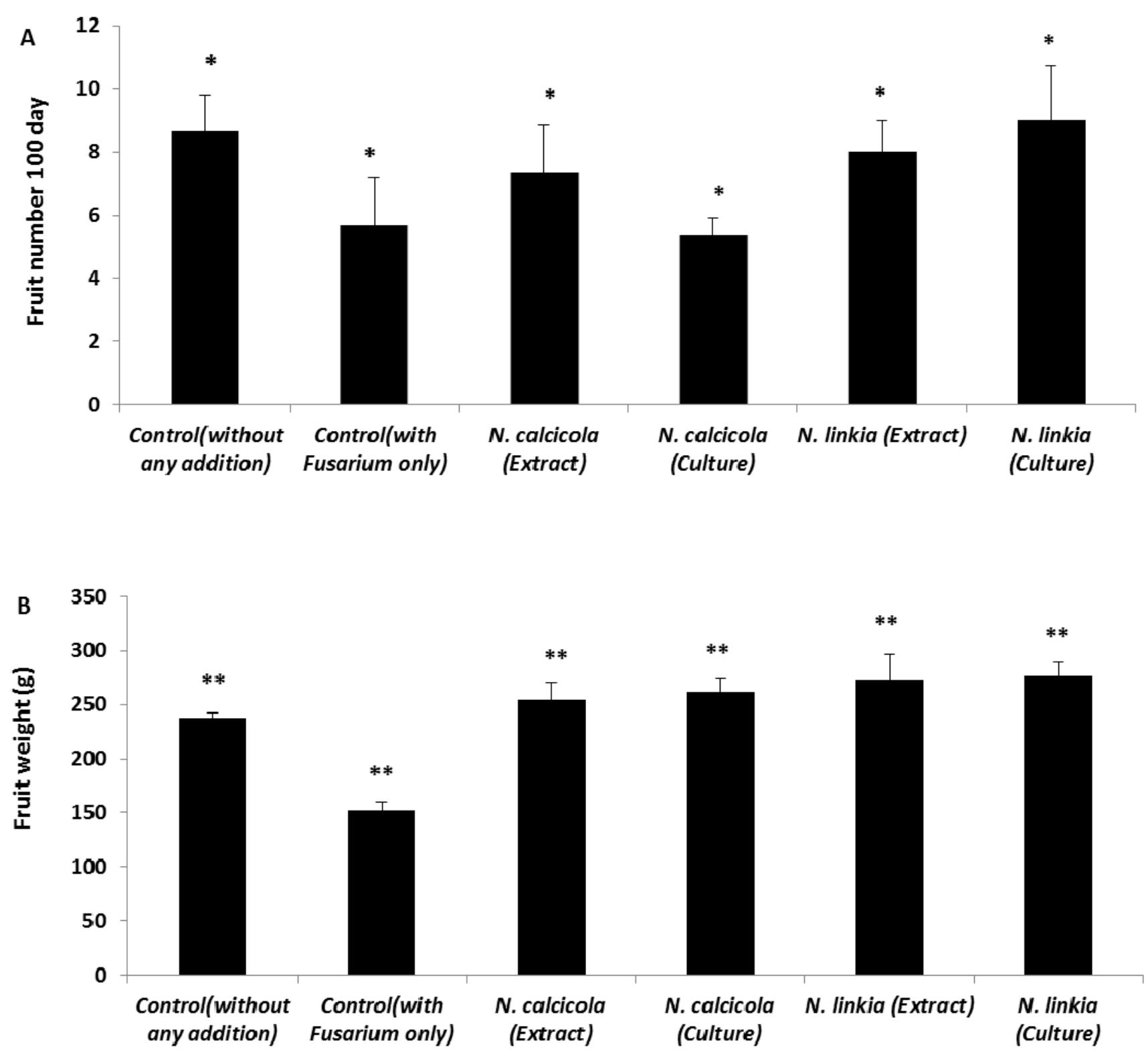

Figure 10

A. Fruit number, B. Fruit weight (g) of tomato after 100 days, * highly significant $p \leq 0.01$, ** very high significant $\mathrm{p} \leq 0.01$. 

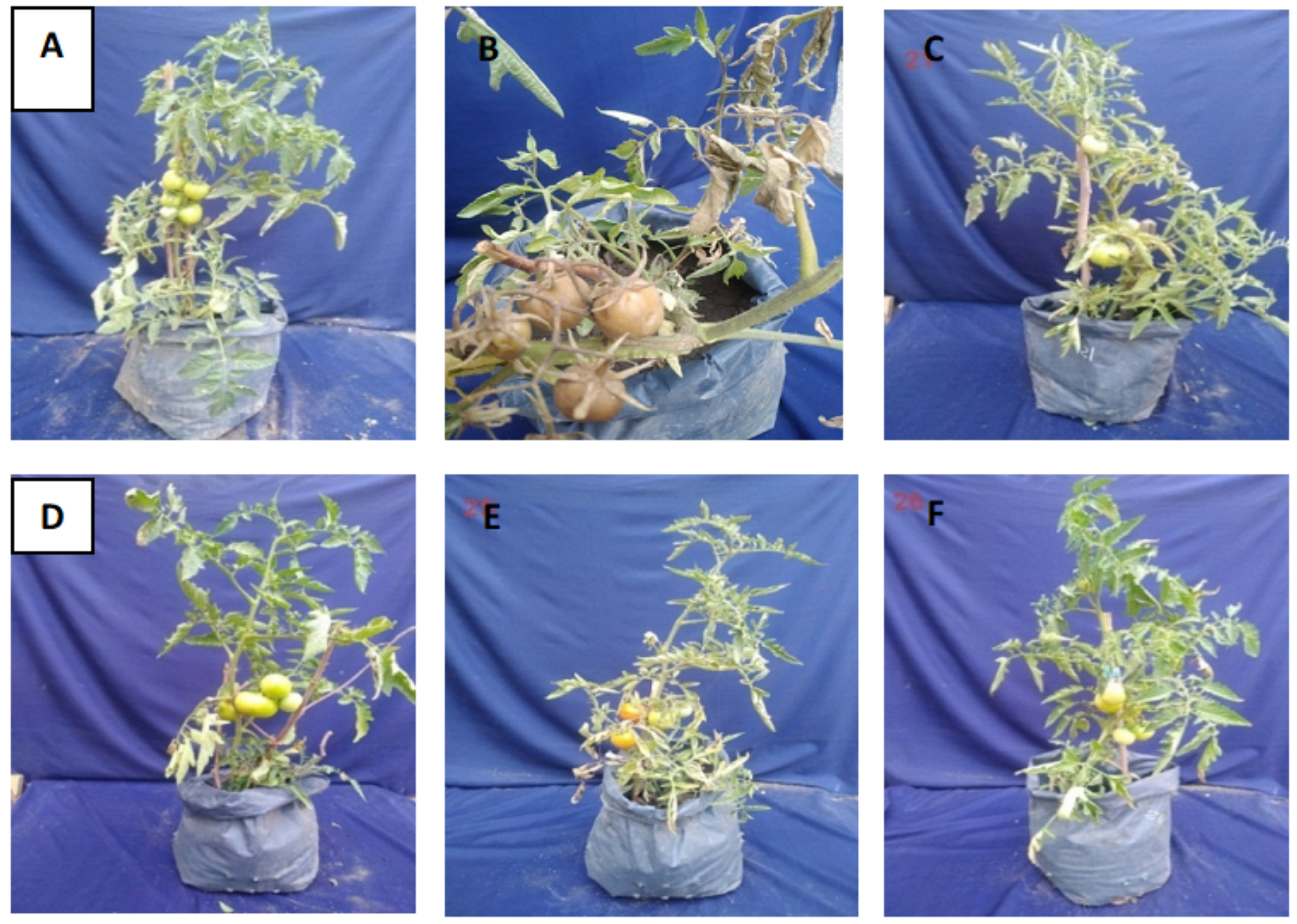

\section{Figure 11}

Pot experiment after 100 days; A- Control 1 (plant without any addition), B- Control 2 (plant infected with FOL), C- N. calcicola extract, D- N. calcicola culture, E- N. linkia extract, and F- N. linkia culture.

\section{Supplementary Files}

This is a list of supplementary files associated with this preprint. Click to download.

- Tables.docx 